\title{
O DIREITO DOS ANIMAIS E AS POLÍTICAS DE SAÚDE PÚBLICA NO CONTROLE DE ZOONOSES: UMA CRÍTICA AO TRATAMENTO DA LEISHMANOISE.
}

\author{
Fernanda Luiza Fontoura de Medeiros ${ }^{1}$ \\ Paloma Rolhano ${ }^{2}$
}

RESUMO

A Constituição Federal de 1988 é clara quanto à concessão da proteção ambiental. Não restam dúvidas acerca da necessidade da tutela jurídica para esse bem tão importante, a fim de que as próximas gerações possuam um meio-ambiente sadio e equilibrado. Contudo, a questão ambiental ultrapassa a seara antropocêntrica e requer uma proteção diferente além daquela apontada pelo homem como necessária. Os animais não-humanos, seres ativamente participantes do meio e de extrema importância para o Ecossistema, necessitam também de uma proteção jurídica. Entretanto, em que pese a existência das mais diversas leis de proteção, tanto a nível constitucional quanto infraconstitucional, bem como produção cientifica e acadêmica no assunto, o poder público ainda insiste em políticas de saúde pública e controle de zooneses ultrapassadas e cruéis aos animais. Desta forma, o presente trabalho busca questionar a efetividade dos tratamentos utilizados no Brasil, discutir a relevância dos mesmos, haja vista a existência de condutas alternativas, que preservam a vida do animal.

Palavras-chave: Direito dos Animais; Proteção Ambiental; Meio-ambiente; Zooneses; Política Pública; Saúde; Transmissão de doenças.

\section{ANIMAL RIGHTS AND THE HEALTH POLITICS ON ZOONOSES CONTROL: A CRITIQUE OF THE TREATMENT OF LEISHMANIASIS.}

\begin{abstract}
The Constitution of the Federative Republic of Brazil of 1988 is clear about the environmental protection. There's no doubt about the need of legal protection for such important matter. However, the environmental issue goes beyond the anthropocentric thoughts and requires a different protection than that the one men establishes as necessary. Animals, beings who are actively participating in the environmental and which are extremely important for the Ecosystem, also need legal protection. Although all the existing laws - at constitutional and infraconstitutional level, and also scientific and academic studies, the public power insists on outdated public health policies, and also cruel to the animals. Thus, this work wants to question the effectiveness of the treatments performed in Brazil, discuss their relevance, considering that there is a lot of alternative conducts, that preserve the animal's life.
\end{abstract}

Keywords: Animal Rights; Environment Protection; Environment; Zooneses; Public Policy; Health; Disease transmission.

\footnotetext{
${ }^{1}$ Doutora em Direito (UFSC). Doutorado Sanduiche (Coimbra). Mestre em Direito (PUCRS). Professora Permanente do Mestrado em Direito (UNILASALLE). Professora Adjunta da FADIR (PUCRS). Coordenadora do Observatório de Justiça Animal.

${ }^{2}$ Bacharel em Ciências Jurídicas e Sociais (PUC/RS. 2011), Mestranda em Direito e Sociedade (Universidade LaSalle/RS) e Advogada.
} 


\section{Introdução}

O tema acerca da proteção ambiental vem sido amplamente discutido, estudado e analisado nos últimos anos, a fim de proteger o meio em que vivemos - devido aos crescentes problemas, tais como poluição do ar, desmatamento, extinção de espécies, entre outros, enfrentado desde a Revolução Industrial. Em que pese o grande cenário que compõe o meio ambiente, temos como de grande importância, a atuação dos animais não-humanos no nosso Ecossistema, vez que resta comprovado que a preservação do planeta depende, também, de suas mais diferentes espécies.

A Constituição de 1988 é um marco para o pensamento sobre os direitos animais no Brasil, mesmo não tendo sido a primeira norma de proteção aos animais não-humanos, foi a primeira Carta a enfrentar o tema de maneira efetivamente vanguardista. Ao proibir a crueldade, o constituinte originário, reconhece ao animal não-humano o direito de ter respeitado o seu valor intrínseco, sua integridade, sua liberdade.

Entretanto, mesmo com os grandes avanços na proteção ambiental com o advento da referida carta, na prática, no que tange a proteção jurídica dos animais não-humanos, o tratamento dispendido é carente, ainda que sérias pesquisas científicas demonstrem que os animais não-humanos são seres sencientes - ou seja, capazes de sentir dor, alegria, sofrimento, amor, raiva, compaixão.

Sendo assim, comprovada sua senciência, bem como sua clara e vasta proteção na Carta Maior, as consequências jurídicas são inúmeras. Ora, evidenciada sua tutela concedida por nossa Constituição, bem como a determinação do art. 225, §1 $1^{\circ}$, inciso VII, é do Estado a titularidade para a proteção da fauna, bem como a vedação de práticas que submetam os animais a qualquer tipo de crueldade. Tal vedação, inclui também às políticas públicas de tratamento a doenças, bem como prevenção a zoonoses.

No que tange a questão das zoonoses no Brasil, temos que a prática utilizada pelo Poder Público a fim de combater a doença da Leishmaniose em cães - qual seja o abate dos mesmos - é extremamente ultrapassada, ineficaz e inconstitucional. Tal conduta possui fundamento no Manual de Vigilância e Controle da Leishmaniose Visceral do Ministério da 
Saúde, de 2006, Decreto 51.838 de 1963 e na Portaria Interministerial n. ${ }^{\circ} 1.426$, de 11 de julho de 2008, que autorizava o sacrifício dos cães por não haver tratamentos alternativos. Contudo, conforme atuais pesquisas científicas substanciais, existe tratamento eficaz e seguro para os cães contaminados. Assim, as diretrizes do Manuel e da referida Portaria não podem ser consideradas métodos de tratamento da doença, mas apenas uma atitude cruel e desorganizada do gestor público.

Nesta seara, o presente trabalho procura demonstrar que um Manual de Vigilância do Ministério da Saúde, bem como a referida Portaria não podem ultrapassar a determinação de proteção do meio ambiente concedida pela lei maior brasileira, vez que há tratamentos alternativos para a doença analisada.

\section{A protecão jurídica dos animais não-humanos no ordenamento brasileiro}

\subsection{A protecão jurídico-constitucional dos animais não humanos na}

\section{Constituição Federal de 1988.}

Em 1988, a Constituição pátria aderiu a um novo plano no que se refere suas normas constitucionais, vez que construiu um capítulo específico acerca da proteção ambiental. Como se sabe, o artigo 225 da CF/88, matriz de toda a proteção ecológica da Nação, afirma o direito de todos ao acesso a um Meio Ambiente ecologicamente equilibrado, essencial à sadia qualidade de vida, impondo-se ao Poder Público e à coletividade o dever de defendê-lo e preservá-lo para as presentes e futuras gerações, considerando-se, inclusive, como um direito fundamental, ante a sua íntima relação para com a efetivação da dignidade da pessoa humana. Para SARLET (2014, p. 51):

(...) Portanto, no contexto constitucional contemporâneo, consolida-se a formatação de uma dimensão ecológica - inclusiva - da dignidade humana, que a grande a ideia em toro de um abem estar ambiental (assim como de um bem-estar social) indispensável a uma vida digna, saudável e segura.

Assim, a partir do inciso VII, do referido artigo 225 do texto constitucional, pode-se afirmar que a referida ordem político-jurídica instituída no Brasil, a partir do Estado Democrático de Direito, elevou a direito fundamental dos animais o tratamento livre de crueldade, se constituindo em dever de todos a defesa e proteção da fauna. Portanto, resta claro que esta regra de vedação de crueldade, como tal, não admite ponderação. Somente 
poderá ser considerada legítima e legal qualquer atividade quando esta não ofender a vedação de crueldade.

Medeiros, na obra Direito dos Animais (2013, p. 111), defende que:

O direito fundamental de proteção ambiental é, como já anunciado, um direito fundamental diferenciado, é um direito que se apresenta a partir de uma nova ótica, haja vista consubstanciar em sua estrutura um direito-dever, calcado na terceira dimensão dos direitos fundamentais, portanto, direito de solidariedade.

No que se refere aos deveres jurídicos dos humanos para com os não humanos, Medeiros (2013, p. 114) novamente assevera que:

Em face da existência do reconhecimento de um valor intrínseco para as demais formas de vida, reconhece-se um dever moral e um dever jurídico dos animais humanos para com os animais não humanos. E tais deveres se descrevem como deveres fundamentais. Portanto, os deveres fundamentais e, em especial, o dever fundamental de proteção aos animais não humanos se consubstanciam na necessidade de limitação e contenção da liberdade de atuação dos animais não humanos, quando suas práticas não estiverem pautadas pelo respeito à vida e à dignidade de todos os membros da cadeia da vida.

Da mesma forma, a Carta Maior incumbiu ao poder público, de forma plena e clara no Art. $225, \S 1^{\circ}$, VII, a titularidade para a manutenção da vedação de crueldade contra os animais não-humanos. Assim, como bem pontua Machado (2009), a referida constituição para além de asseverar o meio ambiente como bem ecologicamente equilibrado, determina que é dever do Poder Público proteger a fauna impedindo as práticas que coloquem em risco sua função ecológica ou provoquem a extinção das espécies. Urge ressaltar que desta forma, a imposição constitucional eleva os animais não-humanos como beneficiários do sistema constitucional e, ao mesmo tempo, estabelece uma nova tarefa estatal e um novo dever fundamental (MEDEIROS, 2013), obrigando ao Poder Público e a coletividade a concretização da norma. De tal modo, cabe ao Estado impedir e reprimir toda e qualquer prática cruel aos seres sencientes.

Medeiros \& Albuquerque (2013, p. 21) defendem que

O grande desafio do Direito contemporâneo é conseguir abraçar os anseios de uma sociedade que está vivenciando mutações do seu modo de agir e de pensar em uma velocidade impressionante. Hodiernamente, (re)pensar a questão dos animais nãohumanos e sua posição no ordenamento jurídico não é mais situação estabelecida em um pequeno nicho e, nessa seara, as provocações por enxergar o Direito de forma 
diferente é quase um imperativo. $\mathrm{O}$ direito à proteção constitucional do ambiente, consubstanciado na prerrogativa de usufruí-lo como um bem ecologicamente equilibrado é fruto da evolução dos direitos, tratando-se de um produto histórico, diferente da proteção jurídica de bens ambientais esparsos nas legislações anteriores. As normas jurídicas de proteção ambiental vêm em resposta a circunstancias sociais e históricas.

Imprescindível destacar que que as inovações da Constituição de 1988 não estão adstritas aos aspectos jurídicos somente. As transformações ocorrem em três dimensões: ética, biológica e econômica. Nessa esteira, conforme Albuquerque (2013), o direito dos animais surge como uma alternativa de dilatação dos fundamentos éticos a fim de abranger os demais animais (para além dos humanos), reconhecendo um direito inerente a todo o reino animal ou, ao menos, aos animais sencientes -.

A proteção animal sob a tutela constitucional delimitou uma nova dimensão do direito fundamental à vida e à dignidade da pessoa humana, uma vez que é um marco para o pensamento sobre os direitos animais no Brasil. Ao proibir a crueldade, o constituinte originário, reconhece ao animal não-humano o direito de ter respeitado o seu valor intrínseco, sua integridade, sua liberdade. Logo, nos casos em que houver condutas alternativas para a utilização de animais, inclusive no tratamento de zoonoses, é dever do Poder Público utilizar o meio mais protetivo e não o mais cruel.

\subsection{Da protecão infraconstitucional dos animais não humanos.}

A proteção infraconstitucional federal do animal não-humano se apresenta no ordenamento jurídico brasileiro desde muito antes da história constitucional recente. Em 1924, o Brasil apresenta a primeira norma que passa a proibir a crueldade contra animais Decreto 16.590, que regulamentava as Casas de Diversões Públicas, proibindo corridas de touros, brigas de galos e canários, dentre outras providências. Em 10 de julho de 1934, por inspiração do então ministro da agricultura, Juarez Távora, o presidente Getúlio Vargas, chefe do Governo Provisório, promulgou o Decreto Federal 24.645, que estabelecia medidas de proteção aos animais. Ainda, em 3 de outubro de 1941, foi baixado o Decreto-Lei 3.688, Lei de Contravenções Penais (LCP), que, em seu artigo 64, proibia a crueldade contra os animais.

Em decorrência de novos fatos cruéis puníveis e de novas exigências sociais, o conceito de crueldade contra animais, sempre abrangendo o de maus-tratos em sua 
generalidade perversa, vem sendo ampliado legalmente no sentido de prever a tendência de novas práticas cruéis contra animais, bem como prevenir e reprimir novas condutas desumanas decorrentes tanto do recrudescimento dos maus costumes como das novas pressões notadamente socioeconômicas e ecológico-ambientais (naturais e culturais) contra tais animais, impondo-se a introdução de novas normas legais e regulamentares ajustáveis as novas exigências de proteção aos animais, de acordo com a realidade contemporânea.

Nesse sentido, a Lei dos Crimes Ambientais (Lei 9605/98) dedica um capítulo aos crimes contra os animais não-humanos, em sua maioria, voltados para a proteção das espécies silvestres da fauna. Ainda, tal lei é de suma importância, uma vez que prevê como crime as atividades danosas contra a fauna. Conforme se depreende da leitura da lei, as penas agora têm uniformização e gradação adequadas e as infrações são claramente definidas. Contrário ao que ocorria no passado, a lei define a responsabilidade das pessoas jurídicas, permitindo que grandes empresas sejam responsabilizadas criminalmente pelos danos que seus empreendimentos possam causar à natureza. Matar animais é crime, exceto para saciar a fome do agente ou da sua família; os maus tratos, as experiências dolorosas ou cruéis, o desmatamento não autorizado, a fabricação, venda, transporte ou soltura de balões, hoje são crimes que sujeitam o infrator à prisão.

\section{Das Leishmanioses: o cão não é o vilão.}

\subsection{O que é a Leishmaniose e seus sintomas}

As leishmanioses são consideradas primariamente como uma zoonose, podendo acometer o homem, quando este entra em contato com o ciclo de transmissão do parasito, transformando-se em uma antropozoonose (MINISTÉRIO DA SAÚDE, 2006). Conforme informa o Ministério da Saúde (2017), a Leishmanoise é uma doença sistêmica, caracterizada por febre de longa duração, perda de peso, astenia, adinamia e anemia, dentre outras manifestações. Quando não tratada, pode evoluir para óbito em mais de $90 \%$ dos casos.

A característica marcante da doença é a ocorrência de sérias lesões na boca e no nariz, podendo estender-se até a faringe, deixando os locais seriamente mutilados e dificultando a respiração e a fala. Ainda, febre intermitente com semanas de duração, fraqueza, perda de apetite, emagrecimento, anemia, palidez, aumento do baço e do fígado, 
comprometimento da medula óssea, problemas respiratórios, diarreia, sangramentos na boca e nos intestinos também são sintomas da doença.

Conforme explica Queiroz et al (2017, p.142) :

\begin{abstract}
A maioria dos casos é de infecção assintomática ou que desenvolvem sintomas moderados ou transitórios como diarreia, tosse seca, adinamia, febrícula, sudorese e discreta hepatoesplenomegalia, que podem evoluir ou não para a forma clássica da doença. O quadro clássico consiste de febre, hepatoesplenomegalia, com esplenomegalia volumosa, perda de peso, tosse, diarreia, dor e distensão abdominal. Icterícia e envolvimento renal têm sido descritos. Na fase mais tardia da doença, os pacientes podem desenvolver edema e ascite.
\end{abstract}

Em regra, interessante apontar que o primeiro sintoma da visceralização é uma febre baixa recorrente, frequentemente, com dois ou três picos diários que persistem com remissões durante todo o curso da infecção da doença. A febre é o sintoma mais notável devido a sua característica irregular ou remitente. A segunda manifestação, em importância, no desenvolvimento do quadro é a esplenomegalia.

\title{
3.1. Da transmissão da doenca
}

As Leishmanioses são doenças infecciosas (ou seja, causada por microrganismos) e não contagiosas - o que significa que não se transmite por contato. Ainda, são doenças vetoriais, transmitidas pela picada de um "mosquito" flebotomíneo do gênero Lutzomyi (MINISTÉRIO DA SAÚDE, 2006, p. 09), que se proliferam em locais sem saneamento básico, com acúmulo de lixo e higiene precária.

Ressalta-se que existem basicamente 2 tipos de Leishmanioses: 1)Leishmaniose Tegumentar ou Cutânea e 2)Leishmaniose Visceral. A Leishmaniose Tegumentar não é doença mortal; já a Leishmaniose Visceral é mortal se não tratada. Entretanto, os exames comerciais disponíveis no mercado não diferenciam entre leishmaniose tegumentar e visceral, seja no ser humano, seja nos animais.

A Leishmaniose Visceral no Brasil é causada pelo protozoário Leishmania chagasi. São protozoários flagelados que se desenvolvem no intestino do flebotomíneo fêmea (mosquito palha) que é hematófaga - chamados de promastigotas, na forma infectante para hospedeiros vertebrados. Esses protozoários entram na corrente sanguínea e, ao invadir as células, perdem o flagelo e passam a ser chamados amastigotas, conforme explicado a seguir. 
O ciclo da transmissão da doença ocorre quando o mosquito-fêmea, ao sugar o sangue de mamíferos infectados, ingere macrófagos parasitados por formas amastigotas da Leishmania. No trato digestivo anterior ocorre o rompimento dos macrófagos liberando essas formas. Reproduzem-se por divisão binária e diferenciam-se rapidamente em formas flageladas denominadas de promastigotas, que também se reproduzem por processos sucessivos de divisão binária. As formas promastigotas transformam-se em paramastigotas as quais colonizam o esôfago e a faringe do vetor, onde permanecem aderidas ao epitélio pelo flagelo, quando se diferenciam em formas infectantes - promastigotas metacíclicas. O ciclo do parasito no inseto se completa em torno de 72 horas.

Após este período, as fêmeas infectantes ao realizarem um novo repasto sangüíneo em um hospedeiro vertebrado, liberam as formas promastigotas metacíclicas juntamente com a saliva do inseto. Na epiderme do hospedeiro, estas formas são fagocitadas por células dos sistemas mononuclear fagocitário. No interior dos macrófagos, no vacúolo parasitóforo, diferenciam-se em amastigotas e multiplicam-se intensamente até o rompimento dos mesmos, ocorrendo a liberação destas formas que serão fagocitadas por novos macrófagos num processo contínuo, ocorrendo então a disseminação hematogênica para outros tecidos ricos em células do sistema mononuclear fagocitário, como linfonodos, fígado, baço e medula óssea. (MINISTÉRIO DA SAÚDE, 2006). Assim, resta claro que o responsável pela transmissão é o mosquito e não os mamíferos infectados.

Ainda, em que pese a transmissão seja feito por um mosquito, urge destacar que a pobreza aumenta o risco de leishmaniose. Machado et al (2016, p 250). assevera que

\footnotetext{
Casas com aglomeração de pessoas e sem condições sanitárias adequadas, criação de animais em regime de subsistência no peridomicílio e mata residual favorecem a dispersão do vetor e sua proximidade ao ser humano (WHO, 2012; Dantas-Torres, 2007). Outro fator que interfere na suscetibilidade das populações às leishmanioses é o estado nutricional do indivíduo. É sabido que condições de pobreza associada a dietas deficientes de proteína, ferro, vitamina A e Zinco aumentam a probabilidade de manifestações clínicas (Dsjeux, 2001).
}

Ainda, cumpre salientar que os parasitos de leishmaniose apresentam uma grande heterogeneidade genética e ecletismo quanto às diferentes ordens de mamíferos que são capazes de infectar (Machado et al, 2016). Esse ecletismo resulta em uma epidemiologia complexa e peculiar de cada área de ocorrência de leishmaniose, na qual somente a detecção 
da infecção por leishmaniose em um mamífero não é suficiente para incriminá-lo como um reservatório (Chagas et al., 1938).

\subsection{A polêmica em relacão aos cães: a crueldade das medidas governamentais de} prevencão à Leishmaniose.

Tendo em vista que o transmissor da moléstia é o mosquito anteriormente citado, a doença pode infectar tanto o ser humano, quanto outros mamíferos. E por isso, torna-se uma questão de saúde pública. Desta forma, a preocupação estatal com a enfermidade em tela é uma realidade.

Devido ao ciclo peculiar da doença, - onde é necessário que um mamífero seja picado pelo mosquito vetor fêmea, que, infectada com o sangue deste mesmo mamífero, ao realizar um novo repasto sangüíneo em um hospedeiro vertebrado, liberará as formas promastigotas metacíclicas juntamente com a saliva do inseto, transmitindo a doença - os animais, em especial os cães, infectados pela Leishmaniose passaram a ser perseguidos. $\mathrm{O}$ argumento utilizado é que a proximidade dos cães aos humanos e a coexistência da doença sugeririam que o cão possa manter e ampliar ciclos instalados no peridomicílio. E assim, o cão doméstico seria então o principal reservatório da enfermidade no Brasil (Deane, 1956).

A partir desses estudos, os órgãos sanitários no Brasil passaram a aplicar medidas de interrupção do ciclo de transmissão focadas na identificação e eliminação (sacrifício) de cães suspeitos. Conforme dispõe o Decreto 51.838, de 1963, “técnicas especiais" são necessárias para o controle da Leishmaniose. Entretanto, tais técnicas consistem apenas em dar ênfase no sacrifício dos cães como medida sanitária profilática, o que apenas comprova o pouco empenho do Governo Federal em atualizar as medidas sanitárias, uma vez que em todos os países afetados pela Leishmaniose esta medida já foi banida ${ }^{3}$.

Vejamos:

\footnotetext{
${ }^{3}$ BRASIL. Tribunal Regional Federal da 3a Região. Sexta Turma. Agravo de instrumento. Ação civil pública. Eutanásia canina como política pública de controle de leishmaniose visceral canina. Providência irreversível e de eficácia científica muito duvidosa (possibilidade de tratamento dos animais). Necessidade de eliminar o inseto vetor do protozoário, e não o cão, que é tão vítima da moléstia como o homem (existência de outros animais que tem a mesma potencialidade transmissiva, mas que não são "incomodados" pela saúde pública). Proibição do holocausto canino: agravo provido. Agravo de Instrumento 405724 no processo de origem no 0013792-50.2010.4.03.0000. Relator Des. Federal Johonsom Di Salvo. 28/05/2015.
} 
Art. $3^{\circ}$ O Departamento Nacional de Endemias Rurais executará as seguintes medidas profiláticas:

a) investigação epidemiológica;

b) inquéritos extensivos para descoberta de cães infectados;

c) eliminação dos animais domésticos doentes;

d) campanhas sistemáticas contra os flibótomos nas áreas endêmicas;

e) tratamento dos casos humanos.

Art. $4^{\circ} \mathrm{O}$ Instituto Nacional de Endemias Rurais realizará isoladamente, ou em conjunto com outros órgãos de pesquisas, as seguintes atividades:

a) inquéritos para a descoberta de animais reservatórios;

b) investigação das espécies transmissoras, sua bionomia e distribuição geográfica.

Art. $5^{\circ}$ A educação sanitária será realizada com objetivo de esclarecer a população sôbre a importância do cão na epidemiologia da doença, ressaltando a necessidade da eliminação do animal doente.

Art. $8^{\circ}$ Nas áreas endêmicas será obrigatório o exame dos cães, visando manter o contrôle da zoonose na população acima.

Art. $9^{\circ}$ Os cães encontrados doentes deverão ser sacrificados, evitando-se, porém, a crueldade.

Destaca-se os arts. $5^{\circ}$ e $8^{\circ}$, diante da contradição que representam no cenário atual. Ora, a educação sanitária é a peça chave como medida preventiva, conforme sustentam as pesquisas científicas atuais a seguir demonstradas. A referida lei tem como foco informar erroneamente, falhando com o princípio da boa-fé, induzindo a população a crer que o problema está no cão, e fazendo recair sobre ele o "controle da zoonose", bem como o claro desrespeito ao art. 225, $\S 1^{\circ}$, VII, da Constituição Federal.

A disposição da Portaria Interministerial 1426, de Julho de 2008 resolve a questão de maneira não menos problemática:

Considerando que não há, até o momento, nenhum fármaco ou esquema terapêutico que garanta a eficácia do tratamento canino, bem como a redução do risco de transmissão;

Considerando a existência de risco de cães em tratamento manterem-se como reservatórios e fonte de infecção para o vetor e que não há evidências científicas da redução ou interrupção da transmissão; 
Considerando a existência de risco de indução a seleção de cepas resistentes aos medicamentos disponíveis para o tratamento das leishmanioses em seres humanos; e

Considerando que não existem medidas de eficácia comprovada que garantam a não-infectividade do cão em tratamento, resolvem:

Art. $1^{\circ}$ - Proibir, em todo o território nacional, o tratamento da leishmaniose visceral em cães infectados ou doentes, com produtos de uso humano ou produtos nãoregistrados no Ministério da Agricultura, Pecuária e Abastecimento (MAPA). (grifo nosso).

A argumentação de que não existem fármacos ou esquema terapêutico para o tratamento dos cães é completamente desatualizada e desinformada. Conforme estudo promovido pela Fundação Oswaldo Cruz, o tratamento existe e é sim eficaz, demonstrando apenas que a política em questão sustenta apenas interesses políticos e não de saúde pública. Machado et al (2016, p. 255) afirma que:

\begin{abstract}
Apesar das evidências científicas contrárias à prática da eutanásia como medida eficaz para o combate à doença e, por consequência, de garantia da saúde pública, a Advocacia Geral da União (Brasil, 2012), em 2012, emitiu um parecer jurídico sustentando que as ações (eutanásia) promovidas para o controle da leishmaniose visceral, por parte do Ministério da Saúde, eram respaldadas por evidências científicas robustas. Contudo, da leitura do parecer, a robustez sustenta-se na opinião de um único especialista contratado pelo próprio Ministério da Saúde. Os elementos de convencimento adotados foram a expansão da doença no país e o seu grau de letalidade. Como conclusão, a Advocacia Geral da União defende "que a eutanásia dos cães infectados pela leishmaniose é medida que se impõe, sob pena de evidente e irreversível prejuízo ao interesse público (aqui representado pela saúde pública e vidas humanas) e caracteriza-se por ser: cientificamente respaldada, indispensável ao êxito das ações e razoável na ponderação dos interesses envolvidos" (Brasil, 2012). O parecer, visto que pautado em uma opinião isolada, desconsiderou evidências científicas que já comprovaram que a estratégia de remoção de reservatórios é menos eficiente do que o controle dos vetores.
\end{abstract}

De acordo com experimentos de 2002, a prevenção da doença com vacinas e uso de inseticidas possui muito mais efeito do que abater os animais. Courtney et al (2002, p.1319) afirma que:

Em uma simulação do impacto de diferentes estratégias sobre a transmissão da leishmaniose foi mostrado que a eliminação de reservatórios vertebrados é muito menos eficiente do que as vacinas, intervenções nutricionais ou o uso de inseticidas (grifo e tradução nossa)

Ainda, no que se refere ao Manual Vigilância e Controle de Leishmaniose Visceral expedido pelo Ministério da Saúde, a previsão também é recheada de barbaridades, conforme dispõem os itens 4.2 e 7.3 : 


\section{Tratamento}

\subsection{No cão}

O tratamento de cães não é uma medida recomendada, pois não diminui a importância do cão como reservatório do parasito. As tentativas de tratamento da leishmaniose visceral canina, por meio de drogas tradicionalmente empregadas (antimoniato de meglumina, anfotericina B, isotionato de pentamidina, alopurinol, cetoconazol, fluconazol, miconazol, itraconazol), tem tido baixa eficácia. O uso rotineiro de drogas em cães induz à remissão temporária dos sinais clínicos, não previne a ocorrência de recidivas, tem efeito limitado na infectividade de flebotomíneos e levam ao risco de selecionar parasitos resistentes às drogas utilizadas para o tratamento humano.

\subsection{Orientações dirigidas ao controle do reservatório canino}

7.3.1 Eutanásia de cães: A prática da eutanásia canina é recomendada a todos os animais sororreagentes e/ou parasitológico positivo.

Entretanto, em nenhum momento, o Manual apresenta dados científicos atuais. Baseia-se em pesquisas ultrapassadas, referidas desde sua primeira edição, datada com mais de dez anos. Ainda, ressalta-se que tal medida não possui comprovação científica de eficácia, pelo contrário, ela tem o potencial de gerar mais danos, sendo que outras medidas de controle foram atestadas cientificamente como eficazes.

Machado et al (2016, p. 251) demonstra que:

Contudo, dados científicos mostram que, apesar das diretrizes bem definidas do Programa de Controle das Leishmanioses (PCL), centradas no tratamento precoce dos casos humanos e diminuição dos riscos de transmissão a partir da eutanásia do reservatório doméstico infectado e controle químico dos vetores, ocorreu um aumento do impacto da doença na saúde pública nacional.

\section{Da ineficácia do sacrifício de cães como medida de prevencão e tratamento}

\subsection{Ausência de comprovacão científica sobre a eficiência do abate como} combate à doença.

Em que pese o governo brasileiro, através de seus ministros e secretarias da saúde, insistam em acatar as pesquisas desatualizadas como panorama para suas leis, os novos estudos devem ser motivo de análise profunda, juntamente com o ordenamento pátrio do país, a fim de que a proteção constitucional finalmente seja cumprida. Ora, em um momento histórico de proteção ao animal não humano bem como comprovações científicas atuais que 
trazem uma alternativa ao sacrifício destes animais, não resta dúvida do caráter ultrapassado e inconstitucional de tais normas.

Machado et al questiona (2016, p. 249)

(...) cabe se perguntar se as pesquisas científicas sobre leishmaniose e o ordenamento jurídico de um Estado Democrático de Direito, o brasileiro, autorizam a adoção da prática de extermínio de animais de estimação, como os cães soropositivos, ou se é necessária uma revisão desse instrumento de política pública por causa do elevado custo emocional para os proprietários desses animais e financeiros para os cofres públicos (grifo nosso).

A doença pode ser perfeitamente controlada através campanhas que combatam o vetor - mosquito palha -, medidas de higiene, saneamento básico, uso de coleiras nos animais, vacinas.

Segundo Saldanha et al,

Diversos trabalhos apontam para um método de uso combinado de estratégias no controle da leishmaniose em abandono da eutanásia (Marcondes et al., 2011; Courtney et al. 2002, Costa, 2011). Merecem destaque aquelas que podem ser decisivas para a saúde pública no combate à leishmaniose: campanhas educativas que orientem a população no combate ao vetor; profilaxia das residências, com medidas de higiene; uso de coleiras com ativo de repelente para cachorros; investimento em pesquisa para elaboração de vacinas; conscientização sobre o perigo da doença e medidas de combate à pobreza $e$ desnutrição. (grifo nosso).

Os autores referidos atestam, ainda, que há evidência cientifica que demonstram que sacrificar cães não diminui a prevalência local de leishmaniose.

Marcondes et al (2011, p. 253) afirma que

Estudo longitudinal sobre a dinâmica populacional em área endêmica para LV (Jequié/BA) também conclui que a eutanásia de cães positivos, mesmo quando realizada com eficiência, não reduz a incidência da leishmaniose visceral canina (doravante, LVC). (grifo nosso)

Ou seja, a insistência da prática da eutanásia, no Brasil, deflagra uma violação do princípio da precaução e da prevenção. A Constituição Federal visa a uma ampla tutela do ambiente natural que não pode ser limitada a uma perspectiva ultrapassada e acomodada do gestor público. 


\subsection{Eutanásia não é sinônimo de sacrifício.}

Com os avanços da Ciência e a existência de medicações que parecem adequadas, o extermínio de cães doentes de Leishmaniose viral como forma de restaurar a Saúde Pública, não tem propósito e cai muito mal diante da constatação de que esse holocausto nada mais é do que triste consequência da absoluta inépcia das autoridades sanitárias em erradicar uma moléstia que é endêmica no Brasil; é mais fácil atribuir aos cães a condição de repositórios do protozoário Leishmania chagasi transmitido pelo "mosquito-palha" e matá-los, do que atuar de forma competente para destruir os criadouros do tal mosquito.

O Ministério da Saúde demonstra-se tão despreparado em relação ao assunto, que, em que pese seu Manual de Vigilância Sanitária prever a eutanásia como uma das únicas - e mais importantes - formas de combate, o site do referido Ministério (2014, p. 01) informa que tal doença, nos humanos, tem cura:

\footnotetext{
Apesar de grave, a Leishmaniose Visceral tem tratamento para os humanos. Ele é gratuito, está disponível na rede de serviços do Sistema Único de Saúde e baseiase na utilização de três fármacos, a depender da indicação médica: o antimoniato de N-metil glucamina, a anfotericina B lipossomal e o desoxicolato de anfotericina B." (grifo nosso).
}

Ora, havendo cura, que sentindo faz aniquilar os animais que são tão vítimas quanto os humanos? Imprescindível ressaltar que palavra "eutanásia" está etimologicamente ligada as expressões "boa morte" ou "morte sem dor". Usualmente, portanto, a eutanásia consiste na conduta de abreviar a vida de um paciente em estado terminal ou que esteja sujeito a dores e intoleráveis sofrimentos físicos ou psíquicos, o que não se verifica no caso da doença discutida.

No caso, o que pretendem essas normas é o extermínio de cães com suposta situação de animais positivados para a leishmaniose visceral canina. Extermínio ou abate seriam termos mais apropriados, uma vez que existir prevenção e tratamento específico para a doença - mesmo quando da contaminação dos animais.

Machado et al (2016, p. 257) alertam 
A eutanásia é cara, laboriosa e tem alta carga emocional para quem perde seu animal. Em vez de alocar recursos na realização do sacrifício animal, parte dessa verba poderia ser utilizada para um programa de política pública preventiva, substituindo a eutanásia por métodos de controle mais eficazes, condizentes com o ordenamento jurídico nacional e os princípios de direito ambiental. A prática oficial extensiva de extermínio de animais de estimação não é condizente com as evidencias cientificas atuais, os valores das ciências e da sociedade brasileira.

Desta feita, pode-se concluir que havendo cura para humanos - e também para os animais -, bem como toda a pesquisa científica atual, conclui-se que a chamada "eutanásia", nada mais é do que um abate dos cães. Apenas sacrifício de cães que podem ser tratados.

\section{Considerações Finais}

O texto constitucional, além de sua proteção ao meio ambiente a partir do artigo 225, também consagra o direito à vida. Uma vez que fez uso somente do vocábulo "vida", e não da expressão "vida humana", demonstra-se que o mesmo fora utilizado de forma geral, não se resumindo apenas à vida dos homens, mas sim a de todos os seres vivos. Tal texto reflete apenas a consciência do país frente aos bens naturais e aos animais. E desta forma, o bem maior de todos é a vida - sendo, pois, dever do Poder Público zelar por ela, de forma ampla.

A adoção da eutanásia de cães soropositivos como instrumento central de política de saúde pública, defendida pelo Ministério da Saúde em seu Manual de Vigilância e Controle da Leishmaniose Visceral, bem como a disposição do Decreto 51.838 de 1963 e da Portaria Interministerial n. ${ }^{\circ} 1.426$, de 11 de julho de 2008, afrontam o reconhecimento dos animais como seres sencientes, bem como o art. 225, §1 ${ }^{\circ}$, VII da Carta Magna, ignorando melhores práticas assentadas em robustas evidências científicas e, consequentemente, em descompasso com o conjunto de normas e princípios que informam o Direito Ambiental brasileiro. Em síntese, as medidas adotadas pelo Ministério da Saúde desrespeitam o preceito de constitucionalidade das ações governamentais e não encontram eco entre as medidas juridicamente aceitáveis para assegurar o direito ao meio ambiente ecologicamente equilibrado para as gerações presentes e futuras.

Ainda, não fosse apenas a inquestionável importância destes cães por sua simples existência, capacidade senciente e importância no meio, as relações entre humanos e animais têm sido reconhecidas como benéficas para a saúde humana. Animais de estimação têm um papel de apoio emocional e social, principalmente para a população mais idosa. Desta forma, 
ao retirar um cão de uma família, por ser considerado um "reservatório de doença", para ser sacrificado, sem qualquer comprovação científica da efetividade dessa norma, bem como havendo tratamentos alternativos, fere-se a dignidade humana, violando, novamente, a Carta Maior.

Imprescindível se faz salientar que ao proibir que o animal seja tratado de forma cruel, a Constituição Federal reconhece ao animal não-humano o direito de ter respeitado o seu valor intrínseco, sua integridade, vida e liberdade. Assim, os cães em questão, animais sencientes, - ou seja, capazes de sentir dor, prazer, raiva, tristeza, entre outros sentimentos -, necessitam de urgência na efetividade da proteção jurídica. O fato das leis ordinárias, portarias e manuais negarem aos animais uma existência digna constitui uma questão de justiça. E mais, é uma questão de justiça urgente, não havendo qualquer razão para que a proteção jurídica não os alcancem, uma vez que expressamente previsto na referida Carta. Portanto, a morte compulsória desses animais, além de gerar um grande custo emocional, afronta os valores constitucionais de bem-estar da vida animal, não podendo e nem devendo mais ser admitida.

\section{Referências Bibliográficas}

ACSELRAD, Henri; MELLO, Cecília Campello do Amaral; BEZERRA, Gustavo das Neves. O que é justiça ambiental. Rio de Janeiro: Garamond, 2009.

ALBUQUERQUE, Letícia. MEDEIROS, Fernanda. CONSTITUIÇÃO E ANIMAIS NÃO-HUMANOS: UM IMPACTO NO DIREITO CONTEMPORÂNEO. Publica Direito. 2013. Disponível em http://www.publicadireito.com.br/artigos/?cod=1845faa2957cb42b. Acesso em 18/05/17.

BAARS, B. J. "There are no known differences in brain mechanisms of consciousness between humans and other mammals", Animal Welfare, 10, Suppl. 1, pp. 3140. (2001).

BRASIL. Constituição Federal de 1988.

BRASIL. Decreto no 51.838, de 14 de Março de 1963. Baixa Normas Técnicas Especiais para o Combate às Leishmanioses. 
BRASIL. Lei dos Crimes ambientais. Disponível em http://www.planalto.gov.br/ccivil 03/leis/L9605.htm . Acesso em 17/05/2017.

BRASIL. Ministério da Saúde. Portal de Saúde. 2017. Disponível em http://portalsaude.saude.gov.br/index.php/o-ministerio/principal/secretarias/svs/leishmaniosevisceral-lv

BRASIL. Secretaria de Vigilância em Saúde. Manual de Vigilância e Controle da Leishmaniose Visceral. Brasília, DF: Ministério da Saúde, 2014

BRASIL. Portaria Interministerial 1426 de 11 de julho de 2008.

BRASIL. Tribunal Regional Federal da $3^{\mathrm{a}}$ Região. Sexta Turma. Agravo de instrumento 405724 (no processo de origem $\mathrm{n}^{\circ}$ 0013792-50.2010.4.03.0000). Relator Des. Federal Johonsom Di Salvo. Diário Oficial 28/05/2015.

CLABORN, D. M. Leishmaniasis: trends in epidemiology, diagnosis and treatment. Rijeka: InTech, 2014.

COURTENAY, O. et al. Infectiousness in a cohort of brazilian dogs: why culling fails to control visceral leishmaniasis in areas of high transmission. Journal of Infectious Diseases, Oxford, v. 186, n. 9, p. 1314-1320, 2002.

DEANE, L. M. Leishmaniose visceral no Brasil. Rio de Janeiro: Serviço Nacional de Educação Sanitária, 1956.

LOURENÇO, Daniel Braga. Direito dos animais: fundamentação e novas perspectivas. Porto Alegre: Sergio Antônio Fabris Editor, 2008.

MACHADO, Carlos José Saldanha et al. O uso de um instrumento de política de saúde pública controverso: a eutanásia de cães contaminados por leishmaniose no Brasil. Saúde e Sociedade, [s.1.], v. 25, n. 1, p.247-258, mar. 2016. FapUNIFESP (SciELO). http://dx.doi.org/10.1590/s0104-12902016146918.

MACHADO, Paulo Affonso Leme. Direito Ambiental Brasileiro. São Paulo: Malheiros, 2009. 
MARCONDES, M. et al. Textbook of zoonoses: biology, clinical practice, and public health control. New York: Oxford University Press, 2011.

MEDEIROS, Fernanda. HESS, Giovana. Proteção jurídica aos animais no brasil: reflexões entre o decreto $n^{\circ} 24.645 / 34$ e o projeto de lei do senado federal $n^{\circ} 351 / 15$. In: CONPEDI, Brasília, 2016. p. 158-173.

MEDEIROS, Fernanda et al. Animais não-humanos e a vedação de crueldade: $O$ STF no rumo de uma jurisprudência intercultural. Canoas: Ed. Unilassale, 2016.

MEDEIROS, Fernanda Luiza Fontoura de. Meio ambiente: direito e dever fundamental. Porto Alegre: Livraria do Advogado, 2004.

MEDEIROS, Fernanda Luiza Fontoura de. O Direito dos Animais. Porto Alegre: Livraria do Advogado, 2013.

NUSSBAUM, Martha C. Fronteiras da Justiça: deficiência, nacionalidade, pertencimento à espécie. São Paulo: Martins Fontes, 2013.

QUEIROZ, Márcia; CORREIA, Jailson; ALVES, João G.B. Leishmaniose visceral: características clínico-epidemiológicas em crianças de área endêmica. Jornal de Pediatria, Recife, vol. 80, nº2, 2004. Disponível em http://www.scielo.br/pdf/jped/v80n2/v80n2a12.pdf

RODRIGUES, Danielle Tetü. O Direito \& os Animais: uma abordagem ética, filosófica e normativa. Curitiba: Juruá, 2012. Dentre outras obras de referência na área.

SARLET, Ingo Wolfgang; FENSTERSEIFER, Tiago. Princípios do Direito Ambiental. São Paulo: Saraiva, 2014.

SINGER, Peter. Ética e prática. São Paulo: Marins Fontes, 2009. 